\title{
The complete mitochondrial genome of the sexual oribatid mite Steganacarus magnus: genome rearrangements and loss of tRNAs Katja Domes*1, Mark Maraun ${ }^{1}$, Stefan Scheu ${ }^{1}$ and Stephen L Cameron ${ }^{2}$
}

Address: ${ }^{1}$ Technische Universität Darmstadt, Institut für Zoologie, Schnittspahnstr. 3, 64287 Darmstadt, Germany and ${ }^{2}$ Australian National Insect Collection and CSIRO Entomology, Black Mountain Laboratories, Clunies-Ross Street, Canberra, ACT 2601, Australia

Email: Katja Domes* - domes@bio.tu-darmstadt.de; Mark Maraun - mmaraun@gwdg.de; Stefan Scheu - sscheu@gwdg.de; Stephen L Cameron - Stephen.Cameron@csiro.au

* Corresponding author

\section{Published: 7 November 2008}

BMC Genomics 2008, 9:532 doi:10.1/86/147|-2164-9-532
Received: 14 May 2008

Accepted: 7 November 2008

This article is available from: http://www.biomedcentral.com/I47I-2/64/9/532

(C) 2008 Domes et al; licensee BioMed Central Ltd.

This is an Open Access article distributed under the terms of the Creative Commons Attribution License (http://creativecommons.org/licenses/by/2.0), which permits unrestricted use, distribution, and reproduction in any medium, provided the original work is properly cited.

\begin{abstract}
Background: Complete mitochondrial $(\mathrm{mt})$ genomes and the gene rearrangements therein are increasingly used as molecular markers for investigating phylogenetic relationships, especially for elucidating deep splits. Contributing to the complete $\mathrm{mt}$ genomes of arthropods, especially Arachnida, available so far, we provide the first complete $\mathrm{mt}$ genome of a sarcoptiform mite species, the sexually reproducing oribatid mite Steganacarus magnus (Acari, Oribatida) which was determined by sequencing of long PCR products.
\end{abstract}

Results: The mt genome of $S$. magnus lacks 16 tRNAs, only those for leucine, histidine, proline, tryptophan, glutamine and serine are present. Within those tRNAs only tRNA-His and tRNA-Pro have kept their original position, the others are translocated. Furthermore, the $m t$ genome of $S$. magnus consists of $13,818 \mathrm{bp}$ and it is composed of 13 protein-coding genes and two genes for the ribosomal RNA subunits that are typically found in metazoan $\mathrm{mt}$ genomes. The gene order in $\mathrm{S}$. magnus differs from the hypothetical ancestral chelicerate arrangement as conserved in Limulus polyphemus: instead of nad I-rrnL-rrnS-LNR-nad2 (tRNAs excluded) S. magnus is nad2-rrnL-nad I-rrnSLNR. Phylogenetic analyses of a concatenated amino acid dataset of all $\mathrm{mt}$ protein-coding genes of 28 arthropod species suggest a sister-group relationship of sarcoptiform and prostigmatid mites (S. magnus and Leptotrombidium).

Conclusion: The mt gene arrangement of $S$. magnus differs from the hypothetical ground plan of arthropods and from that of other mites further contributing to the variety of mt gene arrangements found in Arachnida. The unexpected lack of tRNAs is enigmatic, probably showing that the loss of $\mathrm{mt}$ genes is an ongoing evolutionary process. For solving phylogenetic relationships of oribatid mite lineages and their position within Acari further complete $\mathrm{mt}$ genomes are needed.

\section{Background}

Mitochondria are maternally inherited cell organelles that contain a circular genome of about $14-19 \mathrm{~kb}$ in bilaterian animals; the mitochondrial (mt) DNA in metazoans usually codes for 13 proteins, 22 transfer RNAs (tRNA), two ribosomal RNAs (rRNA; large (rrnL) and small (rrnS) ribosomal subunit) and contains a non-coding control region (LNR) of variable length $[1,2]$. The loss of genes in mitochondria is a commonly recognized and ongoing process in eukaryotes [3]. Eukaryotic mt genomes gener- 
ally contain fewer genes than their free-living bacterial ancestors since the majority of the original $\mathrm{mt}$ proteins are now encoded in the nucleus; this is either caused by the transfer of the original $\mathrm{mt}$ gene to the nucleus or by the replacement of its function by a preexisting nuclear gene [4]. The protein-coding genes which have been retained in $\mathrm{mt}$ genomes are mainly those involved in electron transport and phosphorylation, e.g., cytochrome b (cob) and the cytochrome oxidases ( $\operatorname{cox} 1, \operatorname{cox} 2, \cos 3)$ [4], but their number is variable ranging from three in the malaria parasite Plasmodium falsciparum (Apicomplexa) [5] to 67 in Reclinomonas americana, the earliest branching aerobic protist (Chlorophyta) [6].

In addition to gene loss, the positions of genes relative to each other exhibit frequent rearrangement. While the arrangement of $\mathrm{mt}$ genes is conserved in some lineages of arthropods $[7,8]$, it is highly variable in others [9-11]. In particular, the positions of the relatively small genes for tRNAs frequently vary within and among taxa. The arrangement of the hypothetical ancestor of arthropods is conserved in the horseshoe crab Limulus polyphemus [12], whereas most insect genomes differ from the ancestral state by the location of one tRNA [7].

Oribatid mites (Acari, Oribatida) are soil-dwelling animals that occur in high numbers in almost all terrestrial ecosystems [13]. A characteristic feature of this group is the unusually high percentage of parthenogenetic taxa ( $10 \%$ of all species) and the co-occurrence of sexuality and parthenogenesis in the same habitat [14]. Oribatid mite fossils date back at least 360 million years $[15,16]$ and therefore a number of parthenogenetic lineages of oribatid mites join bdelloid rotifers as "ancient asexual scandals" [17-20]. Since oribatid mites provide insights into the evolution and maintenance of sex, recently much attention has been paid to their phylogeny and radiation [21-24]. However, studies based on single genes such as the ribosomal $18 \mathrm{~S}$ region (18S), the heat shock protein 82 (hsp82), the elongation factor $1 \alpha(e f 1 \alpha)$ or $\operatorname{cox} 1$ could neither satisfactorily resolve phylogenetic relationships [25] nor clarify the number of parthenogenetic radiations [21] nor delineate the age of the group [20]. Since oribatid mites apparently are among the first terrestrial animals (I. Schaefer, R.A. Norton, S. Scheu \& M. Maraun, unpubl. data) and species exhibit different evolutionary mutation rates, lineages are probably vulnerable to long-branch attraction in phylogenetic reconstruction. Therefore, further markers, such as gene rearrangements in $\mathrm{mt}$ genomes, are needed to resolve phylogenetic relationships of oribatid mite lineages, among mite taxa (Acari) and among chelicerates in general.

Until now no complete mt genome of an oribatid mite species was available although mitochondrial genomes have become invaluable phylogenetic markers during the last few years. Complete mt genome sequences are now known for about 150 arthropods, including 26 chelicerates with 15 species of Acari. These 15 acarine genomes represent ten species of ticks (Ixodida, Parasitiformes), two mesostigmate mites (Mesostigmata, Parasitiformes) and three species of the genus Leptotrombidium (Prostigmata, Acariformes). In contrast to other arthropods and Metazoa in general [2], the arrangement of the mt genes differs markedly within and among taxa of Acari. While the ancestral state of arthropods is retained in soft- and prostriate-hard ticks $[8,26]$, there is a major rearrangement shared by all metastriate hard ticks $[26,27]$, and there are numerous, lineage specific rearrangements in the mesostigmate species, such as Varroa destructor [28] and Metaseiulus occidentalis [29], and also in the prostigmate mite genus Leptotrombidium [10]. Since the deep phylogeny of Acari, especially within the large subgroup of Acariformes, is still controversial, synapomorphic rearrangements of $\mathrm{mt}$ genes, if present, would likely allow new insights into phylogenetic relationships.

We report the first mt genome for an oribatid mite, Steganacarus magnus (Nicolet, 1855). The $\mathrm{mt}$ genome of S. magnus is compared with that of other mites and with basal chelicerates to clarify phylogenetic relationships within Acari and Chelicerata in total. We show that the $\mathrm{mt}$ genome of $S$. magnus is slightly rearranged and lacks 16 tRNA genes.

\section{Results and discussion Mitochondrial genome organization}

The mt genome of $S$. magnus is the first genome published for the large mite group of Sarcoptiformes. The complete $\mathrm{mt}$ genome is circular and consists of 13,818 bp [GenBank: EU935607]. It encodes 13 protein-coding genes, two rRNA genes, six tRNA genes and includes a large noncoding control region as well as several size-variable intergene spacer regions (Fig. 1, Additional File 1). Genes are encoded on both strands which is typical for arthropods. Compared to the mt arrangement of the ancestral arthropod, which is conserved in Limulus polyphemus [12], the genome of $S$. magnus is slightly rearranged: instead of nad1-rrnL-rrnS-LNR-nad2 (tRNAs excluded, underlined genes are coded on the minority strand) the gene arrangement is nad2-rrnL-nad1-rrnS-LNR (Fig. 1); all translocated genes have kept their original orientation. Furthermore, the genes for tRNA-Leu, -Trp, -Gln and -Ser are translocated to new positions with tRNA-Ser, -Leu, and -Trp also being inverted relative to the ground plan; only tRNA-His and -Pro remained in their original location.

Rearrangements of genes in mt genomes are useful markers for deep splits within phylogenies [2] although the relative frequency of rearrangements varies among lineages 
Limulus polyphemus

(14,985 bp)

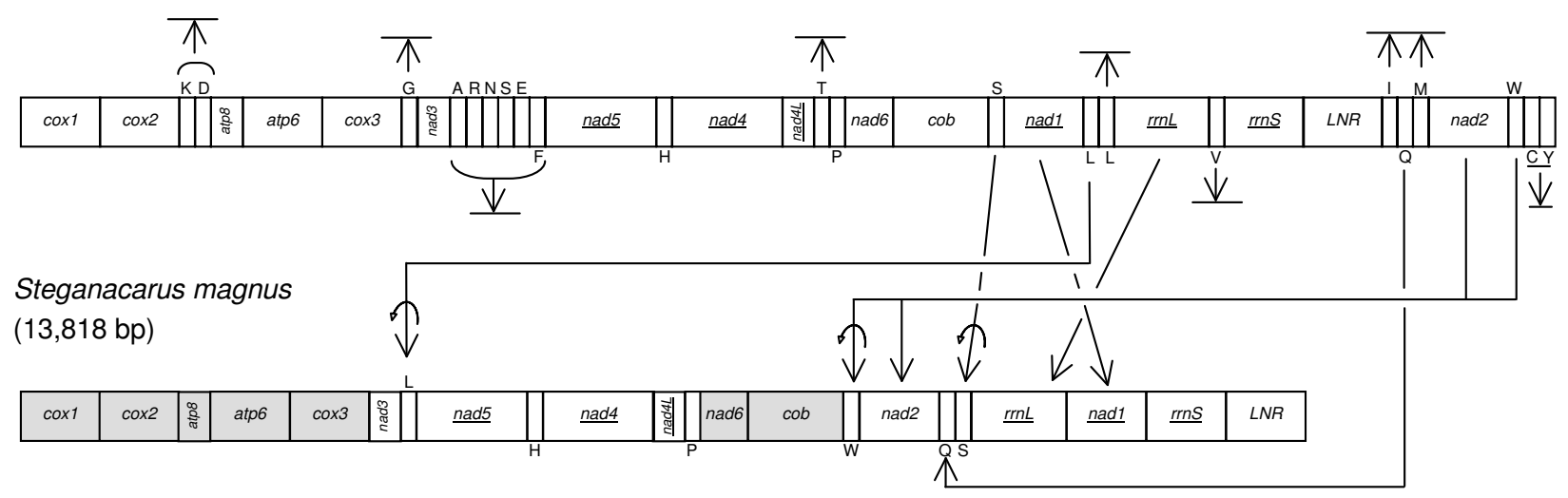

Leptotrombidium akamushi, L. deliense

(13,689 bp and 13,731 bp)

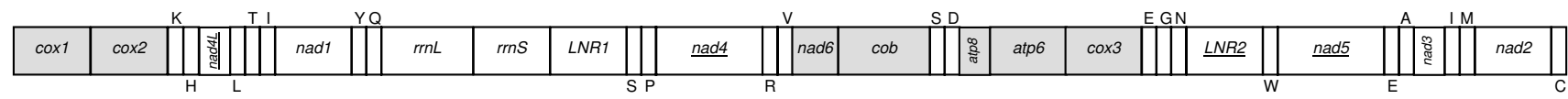

Figure I

Mitochondrial genome organization of Limulus polyphemus, Steganacarus magnus and two Leptotrombidium species. Arrows indicate gene rearrangements (translocations, inversions and loss). Underlined genes and tRNAs with letters below are encoded in the opposite strand. Shaded boxes indicate shared gene boundaries between S. magnus and Leptotrombidium. Gene abbreviations: cox I-3: cytochrome oxidase subunits I-3; atp6,8: ATP synthase subunit 6,8; nad I-6, 4L: NADH dehydrogenase subunit I-6, 4L; cob: cytochrome b; rrnL: large ribosomal subunit; rrnS: small ribosomal subunit; LNR: large non-

coding control region. tRNA genes are symbolised by the one-letter code of their amino acid: $I=I$ soleucine; $Q=G$ lutamine; $M$ = Methione; $\mathrm{W}=$ Tryptophane; $\mathrm{C}=$ Cysteine; $\mathrm{Y}=$ Tyrosine; $\mathrm{K}=$ Lysine; $\mathrm{D}=$ Aspartate; $\mathrm{G}=\mathrm{Glycine} ; \mathrm{A}=\mathrm{Alanine} ; \mathrm{R}=$

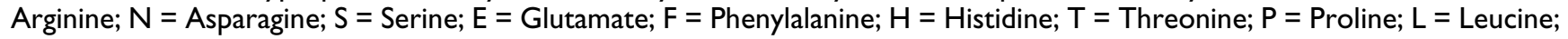
$\mathrm{V}=$ Valine.

[30]. For example, Drosophila (Insecta) and Daphnia (Crustacea) share the same $\mathrm{mt}$ rearrangement although they diverged 400-500 million years ago [30] and the $\mathrm{mt}$ genome of soft ticks remained unchanged for a similar time period [8]. In contrast, gene arrangements in $\mathrm{mt}$ genomes of lice are highly variable $[9,11]$, and in the mite genus Leptotrombidium they even differ between species [10]. In general, in mt genomes of Acari a number of rearrangements have occurred. While the ground plan is retained in soft- and prostriate-hard ticks [26], the arrangement of $\mathrm{mt}$ genes in Mesostigmata (Parasitiformes), especially Metaseiulus occidentalis is strongly derived. Notably, the Metaseiulus $\mathrm{mt}$ genome is the largest within chelicerates, even though nad 3 and nad6 were lost, due to the duplication of many of the remaining genes [29].

Fossils of oribatid mites are known from Devonian sediments and molecular studies suggest that their origin may predate this record by 180 mya (I. Schaefer, R.A. Norton, S. Scheu \& M. Maraun, unpubl. data). Further, oribatids probably diverged from other acariform mites, such as Leptotrombidium, about 570 mya ago (I. Schaefer, R.A. Norton, S. Scheu \& M. Maraun, unpubl. data). The $\mathrm{mt}$ genomes of Leptotrombidium and S. magnus differ markedly; they only share the gene boundaries $\operatorname{cox} 1-\operatorname{cox} 2$, nad6cob and atp8-atp6-cox3 (Fig. 1). However, since these boundaries are also present in the ground plan of chelicerate $\mathrm{mt}$ genomes there are no derived arrangements supporting the common ancestry of Acariformes.

\section{Protein-coding genes and nucleotide composition}

All 13 protein-coding genes typically present in arthropods could be identified in the $\mathrm{mt}$ genome of $S$. magnus. They start with the mt start codons ATT, ATG, ATA and ATC (Additional File 1). Six genes (cox1, atp6, nad3, nad5, $c o b$, nad2) terminate with incomplete stop codons ( $\mathrm{T}$ or TA; Additional File 1) while all others terminate with either TAA, TAG or TTT (atp8, cox3, nad4, nad4L, nad6, nad1; Additional File 1). In cox2, which is flanked by two other protein-coding genes ( $\operatorname{cox} 1$ and atp8), no stop codon is present; as shown for sets of protein-coding 
genes in Anabrus simplex (Orthoptera, Insecta) a stem-loop formation in the secondary structure of the transcribed polycistronic mRNA probably functions as terminator [31].

The percentage nucleotide composition of the $\mathrm{mt}(+)-$ strand is $\mathrm{A}=36.5, \mathrm{C}=13.2, \mathrm{G}=12.2$ and $\mathrm{T}=38.1$. Therefore, there are approximately equal numbers of each complementary nucleotide pairs (A:T, G:C) but a strong ATbias is present. The pattern for all protein-coding genes is also strongly AT-biased but with a much higher T than A content (Additional File 1). Skews calculated for neutral fourfold degenerate sites do not indicate consistent asymmetric strand bias (Additional File 1). Genes encoded on the (+)-strand show either neutral (atp6, nad2), positive (cox2, nad6) or negative CG-skew (cox1, cox3, nad3, cob). The majority of genes encoded on the (-)-strand are positive CG-skewed (nad5, nad4L, nad1) (Additional File 1). The AT skew at fourfold degenerate sites is only positive for nad2 and nad5, but negative for all other protein-coding genes (Additional File 1).

A reversal of the strand bias is usually explained by an inversion of the control region (LNR) which contains the origin of replication and translation [2,32]. During replication the two different strands ((-)- and (+)-strand) are exposed to different mutational pressures, typically causing distinct skews since one strand remains longer in the single-stranded state than the other [33]. Therefore, the LNR likely functions as a key region for determining strand bias and an inversion results in a complete reversal of the strand nucleotide composition over time [33]. In $S$. magnus most genes encoded on the $(+)$-strand show a negative CG-skew at fourfold degenerate third codon positions which is inverted to the common pattern and probably indicates a reversal of the LNR. On the other hand, the presence of neutral or positive skewed genes may indicate that this reversal is of recent origin and consequently the process of inverting nucleotide skew is not completed so far.

The absence of a distinct strand bias can also be explained by the recent inversion of single genes which homogenize general patterns of asymmetry [33,34]. However, since no inversions of protein-coding genes were found in $S$. magnus, the absence of a distinct asymmetrical skew in the genome awaits explanation.

\section{Putative control region}

The major non-coding region (LNR), which presumably functions as the mitochondrial control region, is $1019 \mathrm{bp}$ in length and located between rrnS and cox1 (Fig. 1). There are additional non-coding intergenic regions ranging in size from 2-127 bp. These regions were blasted and checked for tRNA genes but could not be assigned to any functional gene.

The relative location of the LNR varies greatly among invertebrates with the ancestral pattern of arthropods being rrnS-LNR-tRNA-Ile [1,2]. It also varies in length mostly due to different numbers of sequence repeats, and length heteroplasmy within individuals has also been recorded [32]. There was no length heteroplasmy in $S$. magnus but two inverted sequence repeat regions, each with a length of $190 \mathrm{bp}$, were present at positions 133322 (repeat 1) and 830-1019 (repeat 2). The region before repeat 1 contains four stem-loop structures at positions 3-26, 32-56, 60-76 and 82-129 (Fig. 2); the region between the two repeats contains 10-12 stem-loop structures depending on differences in folding. None of the hairpin structures is associated with a poly-A or poly-T stretch which would mark the origin of replication (OR) in insect mt genomes [32] nor with a TATA- or GA(A)Tmotif as present in other arthropods [26]. Since the OR typically is close to the gene of $r r n S$ and repeat regions are posterior to it [32], we assume the first region to be the OR of the mt genome of $S$. magnus.

In the mesostigmate mite $M$. occidentalis the stem-loop structure which probably represents the OR comprises only AT nucleotides but does not have any similarity to sequences from other chelicerates [29]. The LNR of the mite $V$. destructor includes several repetitions of a 157-bp motif and eleven sites of potential stem-loop structures have been identified close to it [28]. In the genus Leptotrombidium, the closest relative to $S$. magnus for which an mt genome is sequenced, the LNR is duplicated (and one is inverted) in L. akamushi and L. deliense and four copies are present in L. pallidum [10,27]. Although mt LNR possess several distinct structural features (e.g., high AT-content, concerted evolution of tandem repeats, stem-loop structures), their use for evolutionary studies is limited by the high variability of the sequence and the possibility of length heteroplasmy within individuals [32].

\section{rRNA genes}

The large subunit of the rRNA ( $r r n L)$ is 992 bp in length (Additional File 1) which is a bit shorter than in other mite species (e.g., about 1,014 bp in Leptotrombidium [10], 1,212 bp in Carios capensis [8]). The 5'-end starts three nucleotides apart from nad1 (encoded on the (-)-strand). The 3'-end was difficult to assign since parts of the last stem-loop structure can be included in the gene for tRNASer (Fig. 3A). The gene for the small subunit ( $\mathrm{rrnS}$ ) is 609 bp in length and located between nad1 and the control region (Additional File 1, Fig. 3B). Both ribosomal subunits have a similar AT content to the protein-coding genes and both are encoded on the (-)-strand as in most species of arthropods and chelicerates (e.g., Limulus, Araneae, 


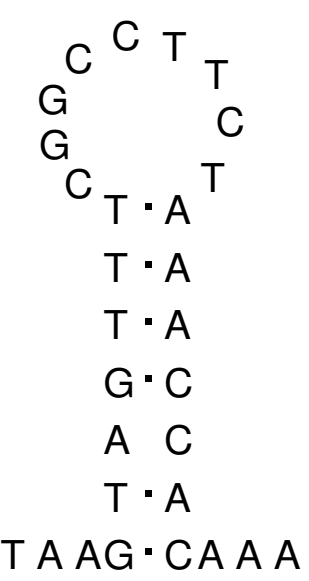

\section{A. Position 3-26}

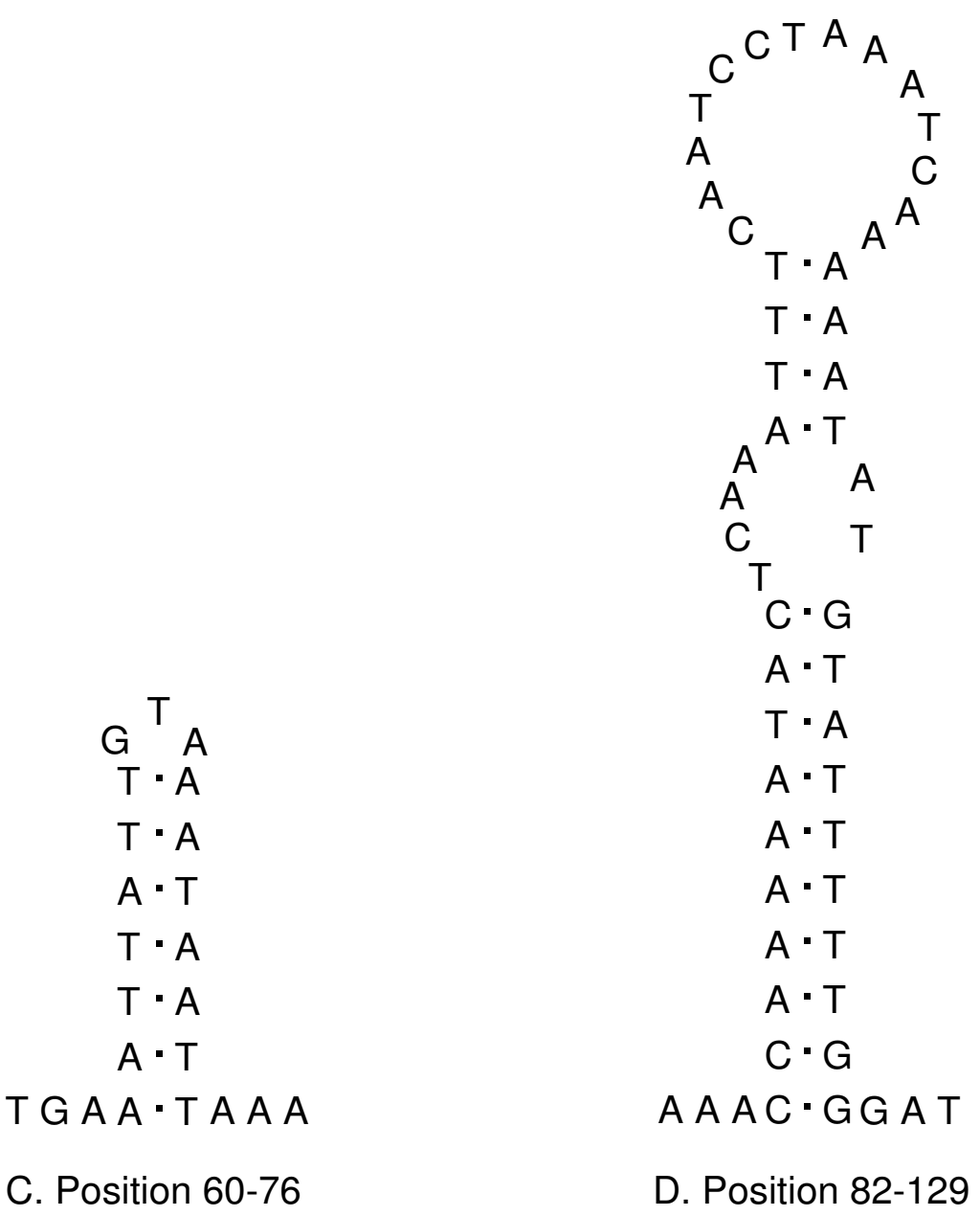

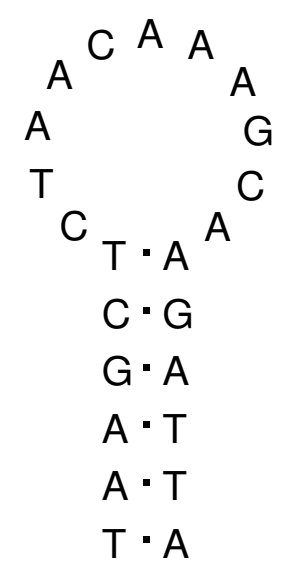

A TTT $\cdot A T G A$

B. Position 32-56

Figure 2

Putative control region secondary structures. Possible stem-loop structures of the origin of replication in the putative control region within the mitochondrial genome of Steganacarus magnus. 
A. large-subunit rRNA

B. small-subunit rRNA
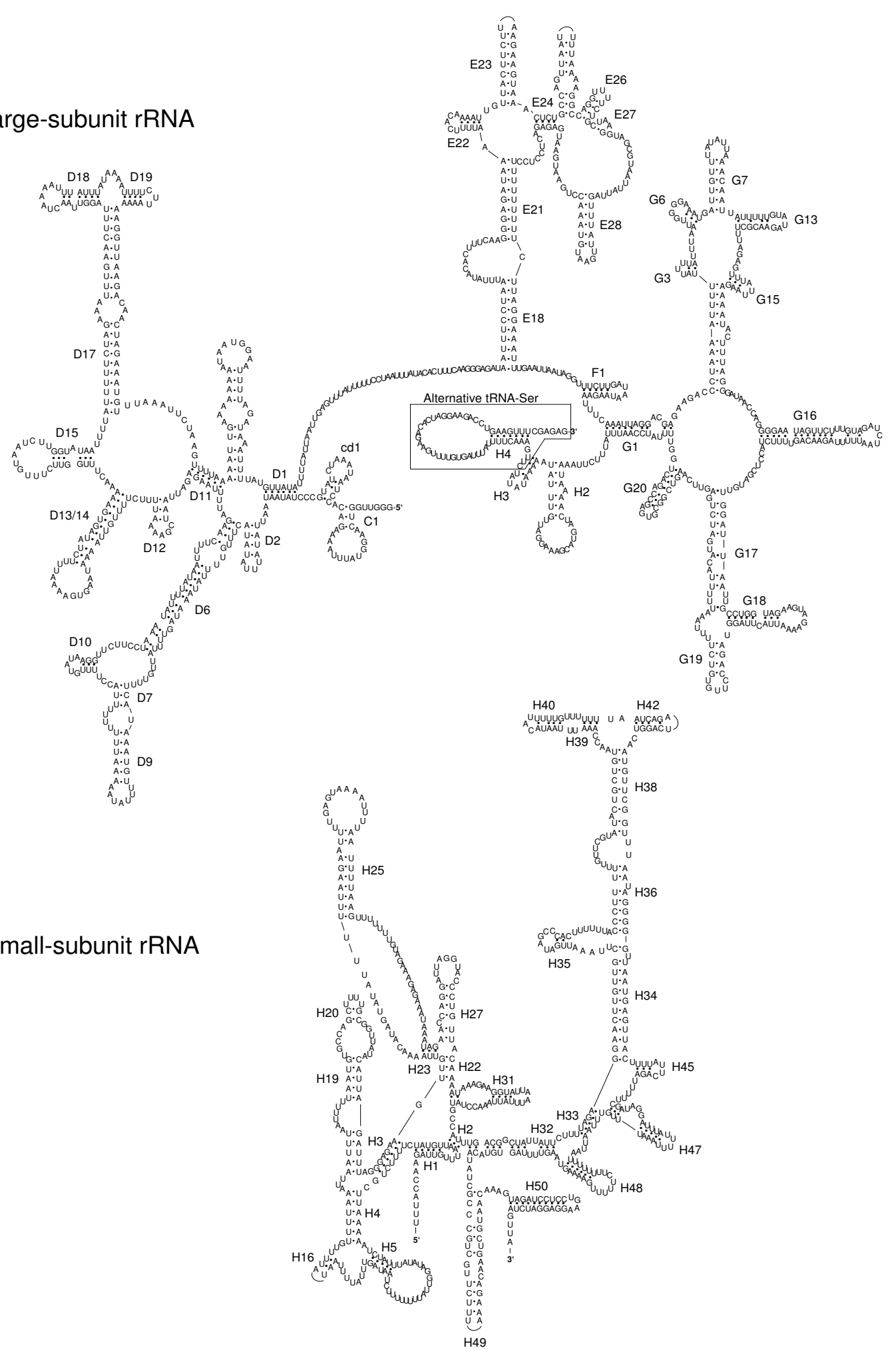

Figure 3

Putative secondary structure of the large- (A) and small-subunit ribosomal RNA (B) of Steganacarus magnus. Dots indicate complementary nucleotide bonds. 
Ricinulei, Pycnogonida, Scorpiones and Ixodidae) [12,26,35-37]. In contrast, in the mt genome of the closely related genus Leptotrombidum as well as in $M$. occidentalis both ribosomal RNA genes are encoded on the $(+)$-strand (but L. pallidum has a duplicated $\mathrm{rrnL}$ gene on the (-)strand) $[10,27,29]$.

The secondary structures of the rRNA genes in Steganacarus differ from those published for Leptotrombidium [10] but are more similar to those published for insects [e.g., $[38,39]]$. The Leptotrombium rrnS gene lacks helices $1,2,4$, $5,7,8$ and 22, and the compound helices 19-20-21 and 39-40-42 as depicted have a very different secondary structure from that found in other arthropods [10]. In contrast, most of the helices found in arthropod rrnS genes are present in Steganacarus, but helices 7 and 8 are absent. However, helix 5 has a large loop such that there is limited difference in sequence length in this region between Steganacarus and arthropods which possess these helices; this is similar to the structure found in Hymenoptera [38]. Helix 16 is greatly shortened relative to other species, consisting of just 2 paired bases compared to up to 8 in Leptotrombidium [10]. The loop regions between helices 38 and 39-40-42 are also greatly reduced consisting of just $4 \mathrm{bp}$ on the 5 ' side and $2 \mathrm{bp}$ on the 3 '; this is in contrast to insects where these loops consist of a dozen or more bases on each side.

Similarly, the rrnL gene of Leptotrombidium entirely lacks domain I (helices B12, B20), helices C1, cd1, D1 and H3 and the structure of the compound helices D17-D18-D19 is unique to Leptotrombidium. The Steganacarus rrnL secondary structure is again more similar to that of other arthropods, domain I is absent but helices C1, cd1 and D1 are present and D17-D18-D19 has a more canonical structure. Helix G3 is greatly reduced, consisting of just 2 paired stem bases and 3 loop bases, relative to both Leptotrombidium, 6 stem and 3 loop bases, and insects, up to 20 stem and 22 loop bases in Manduca [39]. The 3' end of the rrnL molecule is ambiguous, bases 10346-10290 either form the tRNA gene for Serine or they form helices $\mathrm{H} 3$ and the 3' side of H2. Without an analysis of the mature transcribed genes it is not possible to determine which form is more likely in the mature molecule. Helix $\mathrm{H} 3$ is not present in all arthropod $\mathrm{rrnL}$ genes found in Hymenoptera and Lepidoptera but is absent from Coleoptera and Leptotrombidium and its function in the mature rRNA is unclear. Accordingly, we present both possibilities, helices $\mathrm{H} 2$ and $\mathrm{H} 3$ are included in Figure 3 with the region which potentially forms the tRNA shown in a box, while tRNA-Ser is included in Figure 1 and Additional File 1 .

\section{tRNA genes}

Out of the 22 tRNA genes typically present in arthopods only six are present in $S$. magnus. Out of these six tRNAs, only two have kept their original position (tRNA-His between nad5 and nad4, tRNA-Pro between nad4L and nad6 with tRNA-Thr missing) while all others are translocated relative to the ground plan. Further, tRNA-Leu overlaps the nad5 gene by four nucleotides and tRNA-Trp overlaps with the 3 '-end of cob by 16 nucleotides (Additional File 1); as described above tRNA-Ser presumably forms part of the rrnL gene at the 3'-end (Fig. 3A). Remarkably, although 16 tRNA genes have been lost, the mt genome size of $S$. magnus $(13,818)$ is comparable to those of Leptotrombidium deliense $(13,731)$ and L. akamushi $(13,698)[10,27]$ which is due to a larger LNR and more intergenic spacer regions.

All present tRNAs differ remarkably from the typical cloverleaf structure: in tRNA-Leu and -Ser the D-stem and loop are missing and the TyC-stem is short with only two complementary base pairs (Fig. 4). In contrast, the homologous tRNA for leucine in L. pallidum and M. occidentalis lacks the T $\psi \mathrm{C}$ - instead of the D-arm $[27,29]$; while the structure of tRNA-Ser in L. pallidum is similar to that of S. magnus, it differs in M. occidentalis which lacks the T $\psi \mathrm{C}$ arm.

The tRNAs for histidine, proline, tryptophan and glutamine lack the T $\psi \mathrm{C}$-stem and -loop but posses a complete DHU-stem with a smaller loop in tRNA-Trp and a

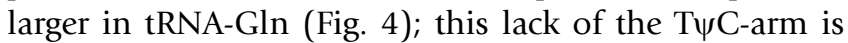
also present in L. pallidum [27] and M. occidentalis [29].

All tRNAs present in $S$. magnus are shorter than the average length of arthropod tRNAs (about $66 \mathrm{bp}$ ) and are highly modified. The loss of the TyC-arm and the replacement by a size-variable loop was first recognized in nematode tRNAs [40] and can also be found in M. occidentalis [29], L. pallidum [10] and other chelicerates including scorpions [35] and spiders [41]. Further, a study on truncated tRNAs in Arachnida revealed that the tRNAs for proline, histidine and glutamine have experienced the greatest number of independent $\mathrm{T} \psi \mathrm{C}$-arm losses in arachnids whereas $\mathrm{T} \psi \mathrm{C}$ arm loss in genes for arginine, lysine and methione have occurred only once and is synapomorphic for opisthothele spiders [42]. However, arachnids seem to have a compensatory mechanism that allows truncated tRNAs to function during translation and the interaction with the ribosome [42].

While the two rRNA genes are present in all eukaryotic genomes [4], the number of tRNA genes varies markedly among taxa. No tRNAs are present in the protists Plasmodium falciparum (Apicomplexa) and Trypanosoma brucei (Kinetoplastida) [43] but up to 27 are present in Reclino- 


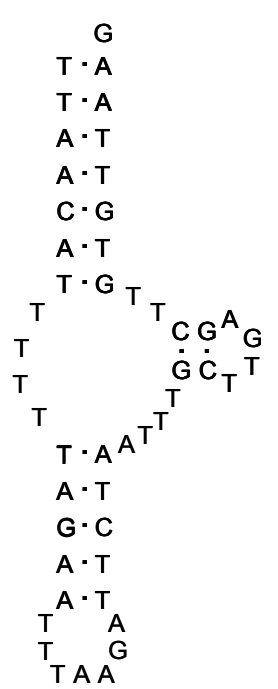

L2

tRNA-Leu(TAA)

4289-4339

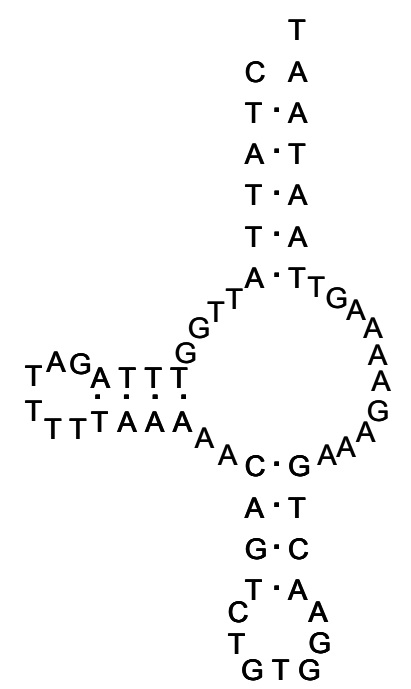

H

tRNA-His(GTG)

5941-5997

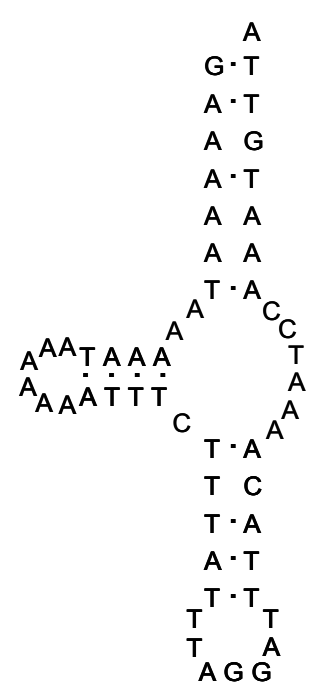

$\mathbf{P}$

tRNA-Pro(AGG)

7526-7581

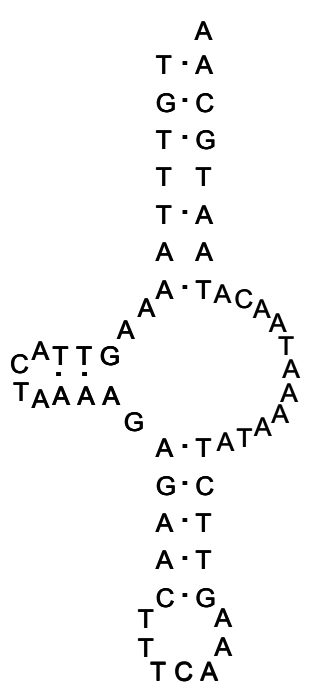

W

tRNA-Trp(TCA)

9051-9106

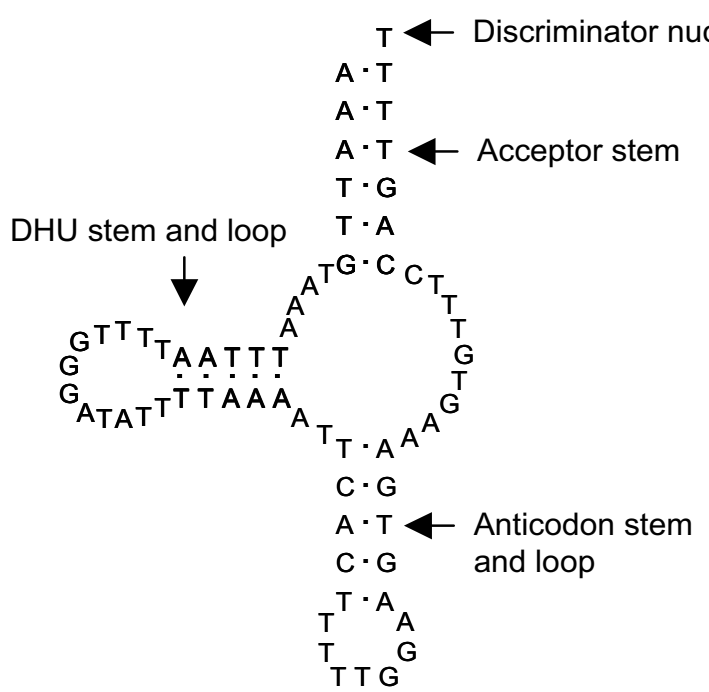

Q

tRNA-GIn(TTG)

10136-10202

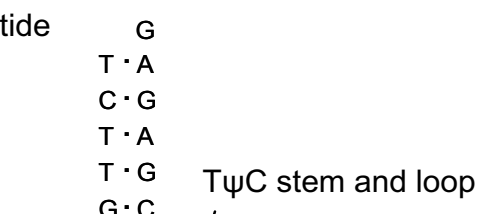

$G \cdot C$

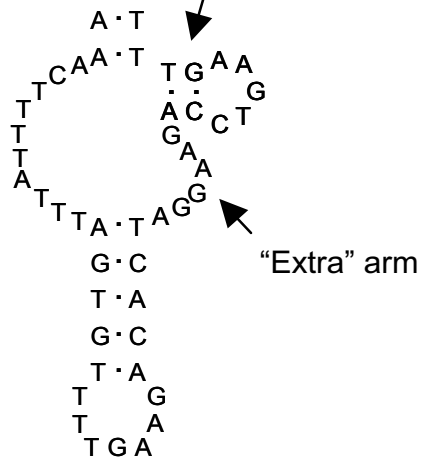

S2

tRNA-Ser(TGA)

10248-10304

Figure 4

tRNA secondary structures of Steganacarus magnus. tRNAs are labelled with the abbreviations of their corresponding amino acids. 
monas americana (Chlorophyta) [6]. The loss of mt tRNA genes may be facilitated by the fact that the proteins with which they interact during translation in the mitochondria are encoded in the nucleus [44]. Furthermore, the mutation rate of $\mathrm{mt}$ encoded tRNA genes is about five-fold higher than that of nuclear genes which experience strong purifying selection $[45,46]$. Since tRNAs are encoded in the nucleus anyway and selective pressure favors the reduction of mt genome size [4], it is likely that $S$. magnus simply lost its tRNA genes instead of transferring them to the nucleus. However, the differences in the genetic code between nucleus (universal code) and mitochondria (invertebrate mt code) would probably argue for two sets of tRNAs or alternatively some modifications of the tRNAamino acyl transferases are needed to treat each tRNA isotype differently in the two different compartments.

\section{Phylogenetic analysis}

Phylogenetic analyses performed on a concatenated dataset of all protein-coding genes (amino acid sequences) included three outgroup species (Daphnia pulex (Crustacea), Penaeus monodon (Crustacea), Lithobius forficatus (Myriapoda)), one species of Solifugae, Xiphosura, and Ricinulei, two Scorpiones species, four species of Araneae and Acariformes and twelve species of Parasitiformes (Fig. 5). All major groups, notably Parasitiformes, Acariformes, Araneae and Scorpiones, were monophyletic and supported by moderate (Araneae) to high (Acariformes, Scorpiones) support values. The sister-group relationship of Scorpiones and Araneae was only supported by posterior probablities (Fig. 5).

The newly sequenced $S$. magnus formed the closest relative of the prostigmate mite genus Leptotrombidium which was expected following previous studies [13]. As in previous studies [36] the ricinuleid species Pseudocellus pearsei clustered as sister-group of Acariformes but was only supported by Bayesian posterior probabilities (Fig. 5). In contrast to the study of Fahrein et al. [36] the Acariformes/ Ricinulei clade did not form the sister-group of Araneae but of Parasitiformes; however, the support for both possibilities is similar weak [see [36]].

For a broader investigation of chelicerate phylogeny $\mathrm{mt}$ DNA data of key taxa such as Opiliones, Pseudoscorpiones, Palpigradi, Uropygi and Amblypygi are missing. Even for a complete study of Acari phylogeny many taxa remain to be sampled; no complete mt genome is available for Astigmata, Endeostigmata or Opilioacarida.

While using mt DNA for phylogenetic studies, a reversal of nucleotide strand bias or a reversal of nucleotide bias of single genes (caused by gene inversion or the inversion of the control region) can be misleading for phylogenetic relationships by causing long-branch attraction artifacts
[34]. Further, since mt genomes evolve at higher rates than the nuclear genome [47], saturation of the phylogenetic signal can also be problematic in deep split phylogenies. Species exhibiting unusual genomic features such as complicated gene arrangements or multiple control regions as well as species with small body sizes or parasitic lifestyle are also vulnerable to long branches [34]. Collectively, Acari exhibit all these features and so a heavy sampling effort will be necessary to reliably use mt genomics in mite phylogenetic studies.

\section{Conclusion}

The first complete mt genome for an oribatid mite ( $S$. magnus, Oribatida, Acariformes) is a typical circular molecule and comprises all protein-coding genes typically present in Metazoa and two genes for the ribosomal subunits. Compared to the putative ground pattern of arthropods the genome is rearranged, affecting the genes nad1, rrnL, rrnS, and nad3. Further, the genome of S. magnus lacks all but six tRNAs, but is comparable in size with genomes of the closely related genus Leptotrobidium; the close relationship of both of these acariform mites was confirmed by phylogenetic analyses using all mt proteincoding genes. Since mt gene arrangements vary strongly among mite species and no full $\mathrm{mt}$ genomes are available for Astigmata, Endeostigmata and Opilioacarida, the use of mtDNA rearrangements for phylogenetic studies is limited at present, especially since gene rearrangements in the studied Acari species do not show a distinct phylogenetic pattern. However, the growing number of published genomes and the better understanding of rearranging mechanisms make mt genomes promising markers for resolving phylogenetic relationships of acarine lineages and Chelicerata in general.

\section{Methods \\ DNA processing}

Specimens of $S$. magnus were collected from the Kranichstein forest located about $8 \mathrm{~km}$ northeast of Darmstadt, Germany. Animals were extracted from leaf litter by heat using a modified Kempson extractor [48], preserved in $75 \%$ ethanol and stored at $-20^{\circ} \mathrm{C}$ until usage. Total DNA was extracted from single specimens using the DNeasy Tissue kit (Qiagen) following the manufactures' protocol (but final elution of DNA was in $40 \mu \mathrm{l}$ instead of $200 \mu \mathrm{l}$ ). Polymerase chain reactions (PCR) were performed for the small ribosomal subunit ( $r r n S)$, the cytochrome b ( $c o b)$ and cytochrome oxidase I ( $\operatorname{cox} 1)$ genes using the primers 12SA and 12SB, CB3 and CB4 and COIarch1 and COIarch2, respectively (Additional File 2). PCR reaction mixtures contained $12.5 \mu$ l HotStarTaq MasterMix (Qiagen), $0.7 \mu \mathrm{l}$ of each primer $(100 \mathrm{pmol} / \mu \mathrm{l})$, and $4 \mu \mathrm{l}$ DNA (unquantified) in a total volume of $25 \mu \mathrm{l}$. Amplification conditions included an initial activation step at $95^{\circ} \mathrm{C}$ for $15 \mathrm{~min}$ followed by 34 cycles of $95^{\circ} \mathrm{C}$ for $45 \mathrm{~s} ; 44^{\circ} \mathrm{C}$ 


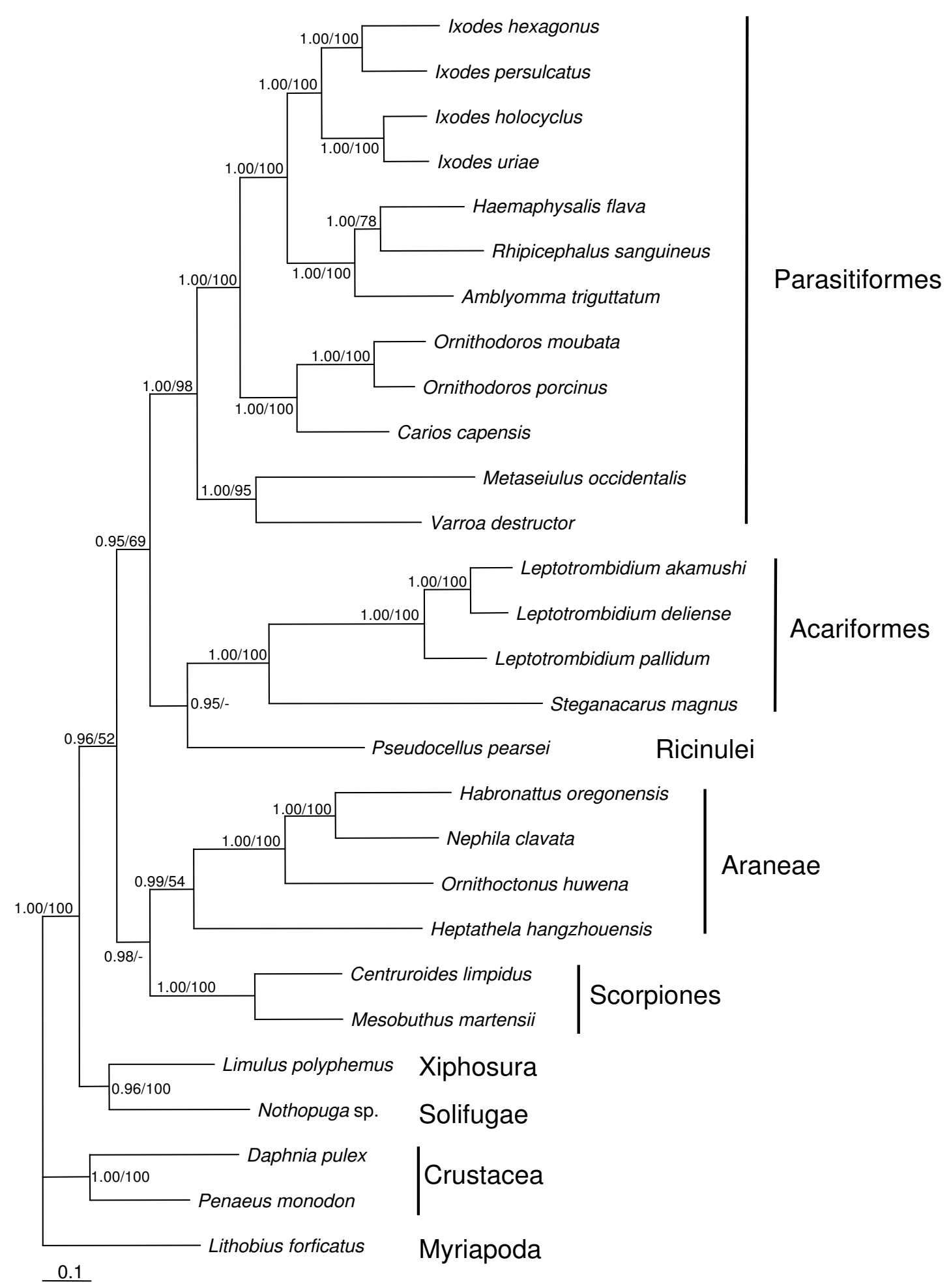

\section{Figure 5}

Bayesian tree phylogeny. Bayesian tree of a concatenated amino acid dataset of all mitochondrial protein-coding genes in the order atp8, atp6, coxl, cox2, cox3, cob, nadl, nad2, nad3, nad4, nad4L, nad5 and nad6 of 28 arthropod species. Myriapoda are used as outgroup. Numbers at nodes represent posterior probabilities for Bayesian analyses and bootstrap support values for neighbor joining. 
$(r r n S), 50^{\circ} \mathrm{C}(c o b)$ or $51^{\circ} \mathrm{C}(\operatorname{cox} 1)$ for $1 \mathrm{~min} ; 72^{\circ} \mathrm{C}$ for 55 $\mathrm{s}$ and a final elongation at $72^{\circ} \mathrm{C}$ for $10 \mathrm{~min}$. PCR products were visualized on a $1 \%$ agarose gel, purified using the QIAquickPCR Purification kit (Qiagen) and directly sequenced by Macrogen (South Korea).

Long PCR amplifications were performed using $1 \mu \mathrm{l}$ Elongase (Invitrogen), $1 \mu \mathrm{l}$ buffer A, $4 \mu \mathrm{l}$ buffer B, $2.5 \mu \mathrm{l}$ dNTPs (25 mM), $1 \mu \mathrm{l}$ of each primer $(10 \mathrm{mM})$ and $1-2 \mu \mathrm{l}$ of DNA (unquantified) with the following conditions: $92^{\circ} \mathrm{C}$ for 2 min; 40 cycles of $92^{\circ} \mathrm{C}$ for $30 \mathrm{~s}, 50^{\circ} \mathrm{C}$ for $30 \mathrm{~s}, 68^{\circ} \mathrm{C}$ for $12 \mathrm{~min}$ and a final extension step of $68^{\circ} \mathrm{C}$ for $20 \mathrm{~min}$. Initial primers for long PCR were designed from the previously obtained sequences of rrnS, cob and cox 1 (Additional File 2). PCR products were visualized on 1\% agarose gels and purified using Millipore Montage vacuum purification plates. Sequencing was performed using ABI BigDye 3.1 dye terminator technology with an ABI capillary sequencer at the John Curtin Medical School sequencing centre (Australian National University). Cycle sequencing reactions contained $1 \mu$ BigDye, $0.5 \mu$ l of the primer $(25 \mathrm{mM})$ and $0.5-1.0 \mu$ lemplate (in a total volume of $3 \mu \mathrm{l}$ ) and amplification conditions were 28 cycles of $94^{\circ} \mathrm{C}$ for $10 \mathrm{~s}, 50^{\circ} \mathrm{C}$ for $5 \mathrm{~s}$ and $60^{\circ} \mathrm{C}$ for $4 \mathrm{~min}$. Within each long PCR product the complete double-stranded sequence was determined by primer walking (a list of all primers is available from the corresponding author upon request). Since PCR amplifications derived from DNA extracted from different specimens the final genome sequence is a consensus from a pool of individuals.

\section{Analysis and annotation}

Data were assembled into contigs using Sequencher ${ }^{\mathrm{TM}}$ version 4.7 (Gene Codes Corperation 2006). Protein-coding genes (PCG) were identified by the comparison of their amino-acid sequences using the blastx search BLAST algorithm implemented at the NCBI website http:// www.ncbi.nlm.nih.gov/ and by eye-comparison with other chelicerate sequences. Annotation of the N- and Cterminal ends of each PCG was checked by comparison with the translated amino acid sequences of homologous mt genes for other chelicerates in MEGA ver. 3.1 [49]; MEGA ver. 3.1 was also used for nucleotide composition analyses.

tRNA genes were initially identified by tRNAScan-SE [50] using both the generalized mitochondrial and the specific nematode mitochondrial tRNA settings and by the program ARWEN [51]. Genes found were adjusted by eye to identify structures more similar to those found in other chelicerates [cf. [42]]. Non-coding regions were also searched by eye for stem-loop motifs which could form part of plausible tRNA-like structures but none were found. While it is possible that additional tRNAs are present but unannotated in the Steganacarus mt genome they cannot be identified at this time.

Candidate rRNA genes were identified by blastn searches and aligned with homologous rRNA genes from other chelicerates and insects. A secondary structure model for each gene was elucidated by comparison to the published rRNA secondary structures for Apis [38], Manduca [39] and Leptotrombidium [10].

For phylogenetic analyses we used the concatenated amino acid dataset of all protein-coding genes previously used by Fahrein et al. [36]; amino acid sequences were choosen since a more conservative and more unambiguous alignment was possible. Sequences were aligned using the default settings in ClustalX 1.81 [52]; the gene order was adapted from Fahrein et al. [36]. Since most parts of the aligned amino acid sequences were unambiguous all parts were included in tree construction. Bayesian phylogenetic analysis was performed with MrBayes v3.1.2 [53] using the mitochondrial genetic code for Metazoa and a haploid ploidy level with two independent runs of $1,000,000$ generations and four chains each; trees were sampled every 500 generations. A majority consensus tree was generated using a burn-in of 200. Phylogenetic trees were also constructed using neighbour-joining (NJ) based on uncorrected p-distances as implemented in PAUP* $4 \mathrm{~b} 10$ [54]. Reliability of the branches was ascertained by bootstrap analyses with 10,000 replicates.

\section{Authors' contributions}

KD carried out the molecular studies, performed the phylogenetic analysis and drafted the manuscript. SLC participated in the design of the study, supervised the lab work and the genome annotation and did the secondary structure analyses; he also co-wrote the manuscript. SS conceived of the study, participated in its design and coordination and helped to draft the manuscript. MM also participated in the design of the study and helped to draft the manuscript. All authors read and approved the final manuscript.

\section{Additional material}

\section{Additional File 1}

Annotation of the mitochondrial genome of Steganacarus magnus. ${ }^{1} A T$ skew $=(A-T) /(A+T),{ }^{2} G C$ skew $=(C-G) /(C+G),{ }^{*}$ skews at 4 -fold degenerate sites.

Click here for file

[http://www.biomedcentral.com/content/supplementary/14712164-9-532-S1.xls] 


\section{Additional File 2}

Initial primers for PCR amplifications of the mitochondrial genome of Steganacarus magnus. $\mathrm{rnS}=$ small ribosomal subunit, $\mathrm{cob}=$ cytochrome b, $\operatorname{cox} 1=$ cytochrome $c$ oxidase subunit $I,{ }^{*}$ used with Steg 5. Click here for file

[http://www.biomedcentral.com/content/supplementary/14712164-9-532-S2.xls]

\section{Acknowledgements}

We thank M. Rosenberger and I. Schaefer for collecting the specimens and for supporting the DNA extractions. We are further grateful to L. Podsiadlowski and colleagues for providing their protein dataset. This study was funded by the German Research Foundation (KD, MM, SS) and the National Science Foundation (SLC grant \# DEB0444972).

\section{References}

I. Wolstenholme DR: Animal mitochondrial DNA: structure and evolution. Int Rev Cytol 1992, I41:173-216.

2. Boore JL: Animal mitochondrial genomes. Nuc Acids Res 1999, 27:1767-1780.

3. Blanchard JL, Lynch M: Organellar genes. Why do they end up in the nucleus? Trends Genet 2000, 16:315-320.

4. Adams KL, Palmer JD: Evolution of mitochondrial gene content: gene loss and transfer to the nucleus. Mol Phylogenet Evol 2003, 29:380-395.

5. Feagin JE: The extrachromosomal DNAs of apicomplexan parasites. Annu Rev Microbiol 1994, 48:8I-I04.

6. Lang BF, Burger G, O'Kelly CJ, Cedergren R, Golding GB, Lemieuy C, Sankoff D, Turmel M, Gray MW: An ancestral mitochondrial DNA resembling a eubacterial genome in miniature. Nature 1997, 387:493-497.

7. Boore JL, Lavrov D, Brown WM: Gene translocation links insects and crustaceans. Nature 1998, 392(6677):667-668.

8. Shao R, Aoki Y, Mitani H, Tabuchi N, Barker SC, Fukunaga M: The mitochondrial genomes of soft ticks have an arrangement of genes that has remained unchanged for over $\mathbf{4 0 0}$ million years. Insect Mol Biol 2004, I 3:219-224.

9. Covacin C, Shao R, Cameron SL, Barker SC: Extraordinary number of gene rearrangements in the mitochondrial genomes of lice (Phthiraptera: Insta). Insect Mol Biol 2006, I 5:63-68.

10. Shao R, Barker SC, Mitani H, Takahashi M, Fukunaga M: Molecular mechanisms for the variation of mitochondrial gene content and gene arrangement among chigger mites of the genus Leptotrombidium (Acari: Acariformes). J Mol Evol 2006, 63:25I-26I.

II. Cameron SL, Johnson KP, Whiting MF: The mitochondrial genome of screamer louse Bothriometopus (Phthiraptera: Ischnocera): effects of extensive gene rearrangements on the evolution of the genome. J Mol Evol 2007, 65:589-609.

12. Lavrov DV, Boore JL, Brown WM: The complete mitochondrial DNA sequence of the horseshoe crab Limulus polyphemus. Mol Biol Evol 2000, I 7:813-824.

13. Walter DE, Proctor HC: Mites: Ecology, Evolution, and Behaviour University of New South Wales Press; 1999.

14. Palmer SC, Norton RA: Taxonomic, geographic and seasonal distribution of thelytokous parthenogenesis in the Desmonomata (Acari: Oribatida). Exp Appl Acarol I991, I 2:67-8I.

15. Krivolutsky A, Druk AY: Fossil oribatid mites. Annu Rev Entomol | 986, 3 |:533-545.

16. Norton RA, Bonamo PM, Grierson JD, Shear WA: Oribatid mite fossils from terrestrial Devonian deposit near Gilboa, New York. J Paleontol 1988, 62:259-269.

17. Mark Welch D, Meselson M: Evidence for the evolution of bdelloid rotifers without sexual reproduction or genetic exchange. Science 2000, 288: |2||-1215.

18. Martens K, Rossetti G, Horne DJ: How ancient are ancient asexuals? Proc R Soc Lond B 2003, 270:723-729.
19. Judson BD, Normark BB: Ancient asexual scandals. Trends Ecol Evol 1996, I I:41-46.

20. Heethoff M, Domes K, Laumann M, Maraun M, Norton RA, Scheu S: High genetic divergences indicate ancient separation of parthenogenetic lineages of the oribatid mite Platynothrus peltifer (Acari, Oribatida). I Evol Biol 2007, 20:392-402.

2I. Maraun M, Salamon J-A, Schneider K, Schaefer M, Scheu S: Oribatid mite and collembolan diversity, density and community structure in a moder beech forest (Fagus sylvatica): effects of mechanical perturbations. Soil Biol Biochem 2003, 35: I 387-I 394.

22. Maraun M, Heethoff M, Schneider K, Scheu S, Weigmann G, Cianciolo J, Thomas RH, Norton RA: Molecular phylogeny of oribatid mites (Oribatida, Acari): evidence for multiple radiations of parthenogenetic lineages. Exp Appl Acarol 2004, 33: I 83-20I.

23. Schaefer I, Domes K, Heethoff M, Schoen I, Norton RA, Scheu S, Maraun M: No evidence for the 'Meselson effect' in parthenogenetic oribatid mites (Oribatida, Acari). J Evol Biol 2006, 19:184-193.

24. Domes K, Norton RA, Maraun M, Scheu S: Re-evolution of sex breaks Dollo's law. Proc Natl Acad Sci USA 2007, I 04:71 39-7| 44.

25. Domes K, Althammer M, Norton RA, Scheu S, Maraun M: The phylogenetic relationship between Astigmata and Oribatida (Acari) as indicated by molecular markers. Exp Appl Acarol 2007, 42:I59-I7I.

26. Black WC IV, Roehrdanz RL: Mitochondrial gene order is not conserved in arthropods: prostriate and metastriate tick mitochondrial genomes. Mol Biol Evol 1998, I 5: I772- I785.

27. Shao R, Mitani H, Barker SC, Takahashi M, Fukunaga M: Novel mitochondrial gene content and gene arrangement indicate illegitimate inter-mtDNA recombination in the chigger mite Leptotrombidium pallidum. J Mol Evol 2005, 60:764-773.

28. Navajas M, Le Conte Y, Solignac M, Cros-Arteil S, Cornuet J-M: The complete sequence of the mitochondrial genome of the honeybee ectoparasite mite Varroa destructor (Acari: Mesostigmata). Mol Biol Evol 2002, 19:23 I3-23I7.

29. Jeyaprakash A, Hoy MA: The mitochondrial genome of the predatory mite Metaseiulus occidentalis (Arthropoda: Acari: Phytoseiidae) is unexpectedly large and contains several novel features. Gene 2007, 391:264-274.

30. Dowton M, Castro LR, Austin AD: Mitochondrial gene rearrangements as phylogenetic characters in the invertebrates: the examination of genomes 'morphology'. Invertebr Syst 2002, I 6:345-356.

31. Fenn JD, Cameron SL, Whiting MF: The complete mitochondrial genome of the Mormon cricket (Anabrus simplex : Tettigoniidae: Orthoptera) and an analysis of control region variability. Insect Mol Biol 2007, 16:239-252.

32. Zhang DX, Hewitt GM: Insect mitochondrial control region: a review of its structure, evolution and usefulness in evolutionary studies. Biochem Syst Ecol 1997, 25:99-120.

33. Hassanin A, Leger N, Deutsch J: Evidence for multiple reversals of asymmetric mutational constraints during the evolution of the mitochondrial genome of Metazoa, and consequences for phylogenetic inferences. Syst Biol 2005, 54:277-298.

34. Hassanin A: Phylogeny of Arthropoda inferred from mitochondrial sequences: Strategies for limiting the misleading effects of multiple changes in pattern and rates of substitution. Mol Phylogenet Evol 2006, 38(I): 100-II6.

35. Dávila S, Piñero D, Bustos P, Cevallos M, Dávila G: The mitochondrial genome sequence of the scorpion Centruroides limpidus (Karsch 1879) (Chelicerata; Arachnida). Gene 2005, 360:92-102.

36. Fahrein K, Talarico G, Braband A, Podsiadlowski L: The complete mitochondrial genome of Pseudocellus pearsei (Chelicerata: Ricinulei) and a comparison of mitochondrial gene rearrangements in Arachnida. BMC Genomics 2007, 8:386.

37. Podsiadlowski L, Braband A: The complete mitochondrial genome of the sea spider Nymphon gracile (Arthropoda: Pycnogonida). BMC Genomics 2006, 7:284.

38. Gillespie JJ, Johnston JS, Cannone JJ, Gutell RR: Characteristics of the nuclear (I8S, 5.8S, 28S and 5S) and mitochondrial (I 2S and I6S) rRNA genes of Apis mellifera (Insecta: Hymenoptera): structure, organization, and retrotransposable elements. Insect Mol Biol 2006, I 5:657-686.

39. Cameron SL, Whiting MF: The complete mitochondrial genome of the tobacco hornworm, Manduca sexta, (Insecta: Lepidop- 
tera: Sphingidae), and an examination of mitochondrial gene variability within butterflies and moths. Gene 2008, 408: I I2-123.

40. Wolstenholme DR, MacFarlane JL, Okimoto R, Clary DO, Wahleithner JA: Bizarre tRNAs inferred from DNA sequences of mitochondrial genomes of nematode worms. Proc Natl Acad Sci USA 1987, 84: 1324-1328.

41. Masta SE, Boore JL: The Complete Mitochondrial Genome Sequence of the Spider Habronattus oregonensis Reveals Rearranged and Extremely Truncated tRNAs. Mol Biol Evol 2004, $21: 893-902$.

42. Masta SE, Boore JL: Parallel evolution of truncated transfer RNA genes in arachnid mitochondrial genomes. Mol Biol Evol 2008, 25:949-959.

43. Gray MW, Burger G, Lang BF: Mitochondrial evolution. Scienc I998, 283:|476-|48|.

44. Clayton DA: Transcription and replication of animal mitochondrial DNAs. Int Rev Cytol 1992, I4 I:2 I7-232.

45. Lynch M: Mutation accumulation in transfer RNAs: molecular evidence for Muller's ratchet in mitochondrial genomes. Mol Biol Evol 1996, I3:209-220.

46. Lynch M: Mutation accumulation in nuclear, organelle, and prokaryotic transfer RNA genes. Mol Biol Evol |997, | 4:9|4-925.

47. Li W-H: Molecular evolution Sinauer Associates, Sunderland, Massachuchetts; 1997.

48. Kempson D, Llyod M, Ghelardi R: A new extractor for woodland litter. Pedobiologia 1963, 3:I-2I.

49. Kumar S, Tamura K, Nei M: MEGA3: Integrated software for Molecular Evolutionary Genetics Analysis and sequence alignment. Briefings in Bioinformatics 2004, 5: 150-163.

50. Lowe TM, Eddy SR: tRNAscan-SE: a program for improved detection of transfer RNA genes in genomic sequence. Nucl Acids Res 1997, 25:955-964.

5I. Laslett D, Canbäck B: ARWEN: a program to detect tRNA genes in metazoan mitochondrial nucleotide sequences. Bioinformatics 2008, 24:172-175.

52. Thompson JD, Gibson TJ, Plewniak F, Jeanmougin F, Higgins DG: The ClustalX windows interface: flexible strategies for multiple sequence alignment aided by quality analysis tools. Nucl Acids Res 1997, 24:4876-4882.

53. Huelsenbeck JP, Ronquist F: MRBAYES: Bayesian inference of phylogeny. Bioinformatics 200I, I 7:754-755.

54. Swofford D: PAUP*: phylogenetic analysis using parsimony (and other methods) Version 4.0 Sinauer Associates, Sunderland, Massachusetts; 1999.

55. Skerratt LF, Campbell NJH, Murrell A, Walton S, Kemp D, Barker SC: The mitochondrial I $2 S$ gene is a suitable marker of populations of Sarcoptes scabiei from wombats, dogs and humans in Australia. Parasitol Res 2002, 88(4):376-379.

56. Pons J: DNA-based identification of preys from non-destructive, total DNA extractions of predators using arthropod universal primers. Mol Ecol Notes 2006, 6:623-626.

57. Folmer O, Black M, Hoeh W, Lutz R, Vrijenhoek R: DNA primers for amplification of mitochondrial cytochrome c oxidase subunit I from diverse metazoan invertebrates. Mol Mar Biol Biotechnol I 994, 3(5):294-299.
Publish with Biomed Central and every scientist can read your work free of charge

"BioMed Central will be the most significant development for disseminating the results of biomedical research in our lifetime. "

Sir Paul Nurse, Cancer Research UK

Your research papers will be:

- available free of charge to the entire biomedical community

- peer reviewed and published immediately upon acceptance

- cited in PubMed and archived on PubMed Central

- yours - you keep the copyright

Submit your manuscript here:

http://www.biomedcentral.com/info/publishing_adv.asp
BiolMedcentral 